\title{
Imperforate hymen and its complications: report of two cases and review of literature
}

\section{Setu Rathod, Sunil Kumar Samal*, Anandraj Rajsekaran, P. Reddi Rani, Seetesh Ghose}

Department of Obstetrics \& Gynecology, Mahatma Gandhi Medical College \& Research Institute, Pillaiyarkuppam607402, Pondicherry, India

Received: 28 July 2014

Accepted: 8 August 2014

\author{
*Correspondence: \\ Dr. Sunil Kumar Samal, \\ E-mail: drsksamal1981@gmail.com
}

(C) 2014 Rathod S et al. This is an open-access article distributed under the terms of the Creative Commons Attribution Non-Commercial License, which permits unrestricted non-commercial use, distribution, and reproduction in any medium, provided the original work is properly cited.

\begin{abstract}
Imperforate hymen is a rare female genital tract malformation, arises as a result of complete failure of the inferior end of the vaginal plate to canalize. We report two cases of imperforate hymen with different presentation. Our first case was a 14 year old girl presented with lower abdominal pain and acute retention of urine with history of cyclical lower abdominal pain for last 6 months. Examination revealed mass of 14 weeks gravid uterus with bulged imperforate hymen. The second case was a 16 year old girl presents with primary amenorrhoea with mass per abdomen. There was history of difficulty in micturition and constipation for last 4 months. On examination, a mass of size corresponding to 22 weeks gravid uterus with bulged bluish colour imperforate hymen was found. Both the cases were managed with incision and passive drainage of collected menstrual blood. On follow up both the cases resumed menstruation and doing well.
\end{abstract}

Keywords: Imperforate hymen, Primary amenorrhea, Acute urinary retention

\section{INTRODUCTION}

Imperforate hymen is the commonest female genital tract malformation and is noted in approximately 1 in 2000 females. ${ }^{1}$ Although the most common age of presentation is around puberty ${ }^{2,3}$ diagnosis in utero ${ }^{4-6}$ and during the new born period and childhood ${ }^{4,7}$ are also reported. We report two cases of imperforated hymen with different symptoms of presentation.

\section{CASE REPORT}

\section{Case 1}

A 14 year old girl presented with colicky lower abdominal pain and acute retention of urine for one day. She had not attended her menarche but had developed secondary sexual characters. There was history of cyclical colicky lower abdominal pain with backache for which she took medication from local hospital. For last one month there was increased frequency and difficulty in micturition. Although she had reduced appetite and poor intake of food due to colicky pain, there was no history of constipation, diarrhoea, vomiting or fevers.

She was catheterised with an indwelling Foleys catheter and one litre of straw coloured urine was drained. Abdominal examination revealed, pain and tenderness in lower abdomen with a suprapubic mass corresponding to a uterus at 14 weeks. Examination of external genitalia revealed a bulging bluish colour imperforate hymen (Figure 1) which was exaggerated on valsalva manoeuvres. The mass was found to be anterior to rectum in per rectal examination. Pelvic ultrasonography revealed distended uterus and vagina all filled up with homogenous thick fluid with internal echos (Figure 2). She was diagnosed as a case of hematometra and hematocolpos with imperforate hymen and planned for 
incision and drainage. In operation theatre, a cruciate incision was given and $800 \mathrm{ml}$ of thick tarry blood was drained. The quadrants of the hymens are excised; the mucosal margins were everted and anchored by fine delayed absorbable suture (Vicryl 2/0). Local analgesic cream and prophylactic oral antibiotics were prescribed. Postoperative period was uneventful and she was discharged on $2^{\text {nd }}$ postoperative day after removal of catheter. Follow up after one month revealed patent outflow tract and consummation of normal menstrual cycle.

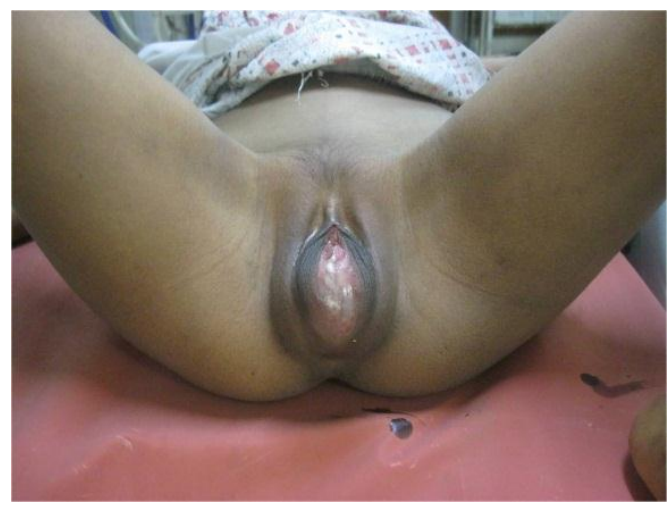

Figure 1: 14 year old girl with bluish bulged imperforate hymen with associated vulvar distension.

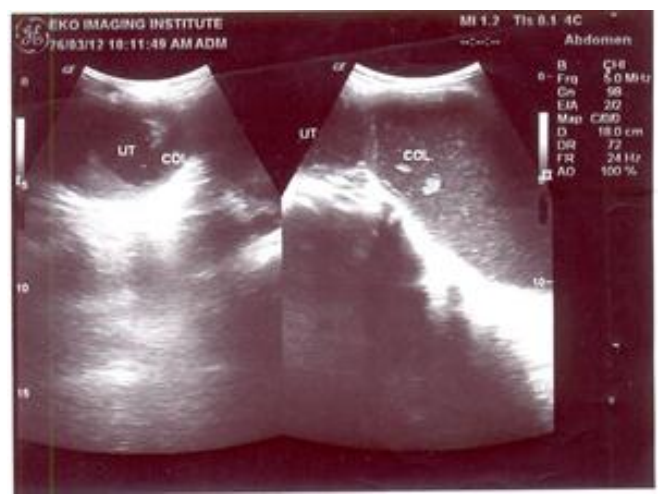

Figure 2: Ultrasound scan showing hematometra and hematocolpos.

\section{Case 2}

We report a case of 16 year old girl who presented with primary amenorrhoea and mass per abdomen. She had history of colicky cyclical lower abdominal pain 4 months back for which she was treated in a local peripheral hospital after which pain subsided. She gave history of difficulty in micturition, constipation and occasional pain in back for last 4 months.

Examination revealed well developed secondary sexual characters with tanner stage IV breast, pubic and axillary hair. On per abdominal examination, the size of mass corresponds to 22 weeks gravid uterus and it was well defined, mobile, tender with non-palpable lower border.
Examination of genitalia revealed bulged blush colour imperforated hymen (Figure 3) and per rectal examination revealed that the mass was anterior to rectum. Abdominal and pelvic ultrasonography revealed large fluid collection in dilated and enlarged vagina, uterus and tubes with fine internal echo's suggestive of hematocolpos, hematometra with hematosalpinx (Figure 4 \& 5). Bilateral mild hydroureteronephrosis due to mass effect of the lesion with no free fluid in peritoneal cavity was reported in ultrasound. CT scan revealed no associated Mullerian duct and skeletal anomalies. She was planned for incision and drainage. In theatre, $\mathrm{X}$ shaped or cruciate incisions was made through the hymenal membrane at the 2-, 4-, 8-, and 10-o'clock positions after putting an indwelling Foleys catheter and $1000 \mathrm{ml}$ of collected chocolate coloured blood was drained passively (Figure 6). The individual quadrants were excised along the lateral wall of the vagina, avoiding excision of the vagina. Margins of vaginal mucosa were approximated with fine delayed-absorbable suture (Figure 7). Local analgesic cream and oral antibiotic were given. She had an uneventful postoperative period and was discharged on $2^{\text {nd }}$ postoperative day after removal of the catheter. She had menstruation after one month and is doing well in follow up examination.

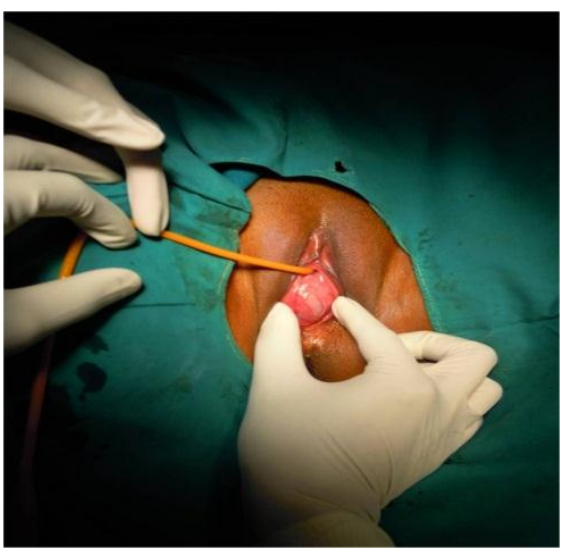

Figure 3: 16 year old girl with imperforate hymen presented as a case of primary amenorrhoea and mass abdomen.

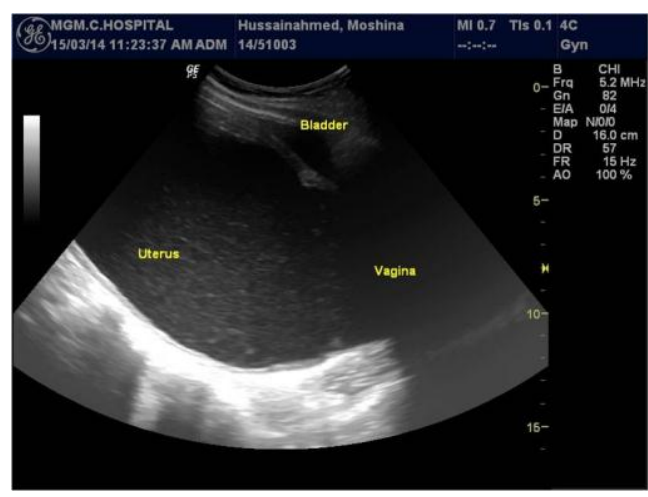

Figure 4: Ultrasound scans showing hematometra and hematocolpos. 


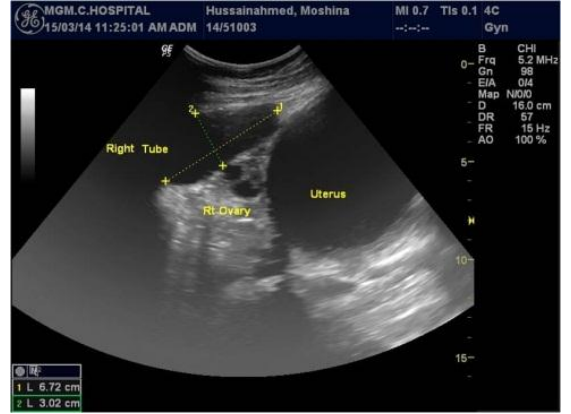

Figure 5: Ultrasound scans showing hematometra and right hematosalpinx with normal ovary.

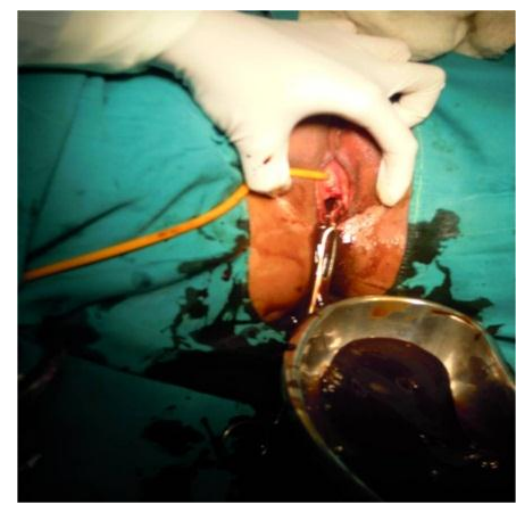

Figure 6: Passive drainage of chocolate coloured altered blood after cruciate incision.

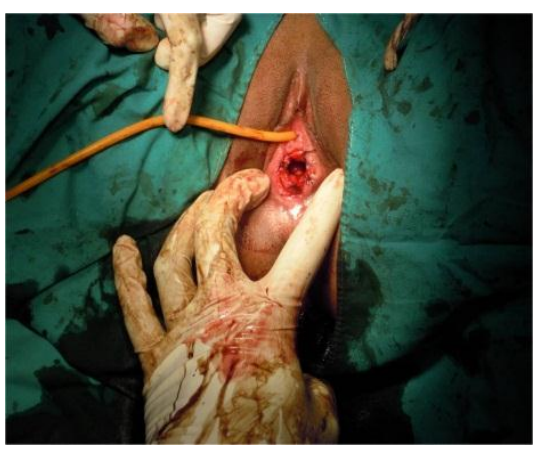

Figure 7: Mucosal margins are approximated with fine delayed-absorbable suture.

\section{DISCUSSION}

The hymen is the membranous vestige of the junction between the sinovaginal bulbs and the urogenital sinus. It generally becomes perforate or patent during fetal life to establish a connection between the vaginal lumen and the perineum. Imperforate hymen is due to complete failure of the inferior end of the vaginal plate to canalize. ${ }^{1}$ Although most cases occur sporadically, cases of imperforate hymen involving multiple family members have been reported. ${ }^{8}$ The function of the hymen is not clear but is thought to include innate immunity as it provides a physical barrier to infections during the prepubertal period when the vaginal immunity is not fully developed. ${ }^{4}$
Imperforate hymen is rarely associated with other female genital tract malformations ${ }^{2,3}$ although some authors ${ }^{9,10}$ have emphasized the need to rule out associated Mullerian malformations. If the hymen is imperforate, mucus and blood from endometrial sloughing accumulate in the vagina which can present during three main stages in life. As congenital hydrometrocolpos in intrauterine period which is the rarest and occurs due to maternal estrogenic stimulation that leads to uterovaginal secretions filling up the blind vagina and diagnosed through obstetric ultrasound. ${ }^{6}$ The diagnosis should be confirmed postnatally. In new-born and childhood period this may occur due to maternal estrogenic stimulation that leads to uterovaginal secretions filling up the blind vagina and presenting with hydrocolpos. ${ }^{2,4,7}$ However, more commonly adolescent girls present after menarche when menstrual blood trapped in the vagina behind the imperforate hymen which is known as hematocolpos creating a bluish bulge at the introitus. With cyclic menstruation, the vaginal canal becomes greatly distended, and the cervix may begin to dilate and allow formation of a hematometra and hematosalpinx.

The age of presentation (mean, range) is 12 and 10-15 years respectively according to Lui et al. ${ }^{10}$ and 13.2 and 11-16 years respectively according to Liang et al. ${ }^{5}$ The common mode of presentation of imperforate hymen includes-

I. Amenorrhea, which may be primary due to accumulation of blood behind the imperforate hymen ${ }^{3,4,7}$ or secondary which can occur following spontaneous closure of previously perforate hymen. The later mainly occurs in micro perforate or stenosed hymen following surgical or sexual trauma where initial light periods will be experienced but continuous stenosis leads to complete obstruction and amenorrhea. ${ }^{11}$

II. Recurrent cyclical lower abdominal/pelvic pains (up to $60 \%)^{3,7,9}$ due to continued distension of the vagina and uterus by accumulating menstrual blood and low back pain $(38-40 \%)^{3}$ which is a referred pain following irritation of the sacral plexus and nerve roots by the distended vagina and uterus.

\section{Obstruction}

1. Urinary outflow obstruction and its complications $(58 \%){ }^{10}$

A. Acute retention of urine $e^{7,10,12}$ which is due to pressure on the bladder by the distended uterus causing angulation at the bladder neck and kinking of the urethra $^{12}$ and direct pressure on the urethra causing urethral tamponade. ${ }^{13}$

B. Chronic or prolonged urinary retention leading to hydroureteronephrosis, ${ }^{9}$ acute bacterial nephritis ${ }^{14}$ and renal failure ${ }^{2}$

2. Vaginal outflow obstruction which is seen as a bluish bulge at the introitus. ${ }^{13}$ 
3. In chronic cases intestinal obstruction leading to constipation $(20-27 \%)^{10}$ and tenesmus ${ }^{13}$ also seen.

4. Lymphovenous obstruction due to compression of the pelvic veins and lymphatics can lead to edema of limbs. ${ }^{2}$

IV. Mass per abdomen due to distended uterus and vagina with accumulated menstrual blood. ${ }^{10}$

V. Retrograde menstruation may lead to the development of endometriosis and laparoscopy can be performed at the time of excision of an imperforate hymen to detect this. ${ }^{1}$

Differential diagnosis of imperforate hymen includes other obstructive reproductive tract anomalies like lower transverse vaginal septum. The associated vulvar distension, however, uniquely suggests imperforate hymen. ${ }^{1}$ Imperforate hymen is usually a clinical diagnosis which can be confirmed by ultrasonography.

The treatment includes surgical hymenotomy under anaesthesia following catheterisation with an indwelling Foleys catheter to re-establish vaginal outflow. An Xshaped incision at 2-, 4-, 8-, and 10-o'clock positions is used which has the advantage of decrease risk of injury to the urethra. The quadrants of the hymen are then excised, and the mucosal margins are approximated with fine delayed-absorbable suture. ${ }^{15}$ Pressure on the uterus in order to expel more blood is discouraged as it can lead to retrograde flow through the tubes causing endometriosis and tubal adhesions. ${ }^{13}$ Needle aspiration of mucocolpos or hematocolpos should be avoided as in can lead to infection and pyocolpos formation. ${ }^{1}$ The outcome of surgical hymenotomy is good and the recurrences are rare. ${ }^{5}$

\section{ACKNOWLEDGEMENTS}

We would like to thank the dept. of obstetrics \& gynecology, SCB medical college, Cuttack and Mahatma Gandhi medical college and research institute, Puducherry for their valuable support and co-operation of patients and their families admitted to these hospitals.

Funding: No funding sources

Conflict of interest: None declared

Ethical approval: Not required

\section{REFERENCES}

1. Schorge JO, Schaffer JI, Halvorson LM, Hoffman B, Bradshaw K. Anatomic disorders. In: Schorge JO, eds. Williams Gynecology. 1st ed. New York: McGraw Hill Medical; 2008: 412-413.

2. Nagai K, Murakami Y, Nagatani K, Nakahashi N, Hayashi M, Higaki T, et al. Life threatening acute renal failure due to imperforate hymen in an infant. Pediatr Int. 2012;54(2):280-2.

3. Dane C, Dane B, Erginbas M, Cetin A. Imperforate hymen-a rare cause of abdominal pain: two cases and review of the literature. J Pediatr Adolesc Gynecol. 2007;20(4):245-7.

4. Basaran M, Usal D, Aydemir C. Hymen sparing surgery for imperforate hymen: case reports and review of the literature. J Pediatr Adolesc Gynecol. 2009;22(4):61-4.

5. Liang CC, Chang SD, Soong YK. Long-term followup of women who underwent surgical correction for imperforate hymen. Arch Gynecol Obstet. 2003;269:5-8.

6. Ayaz UM. Ultrasonographic diagnosis of congenital hydrometrocolpos in prenatal and newborn period: a case report. Med Ultrasonography. 2011;13(3):2346.

7. Ercan CM, Karasahin KE, Alanbay I, Ulubay M, Baser I. Imperforate hymen causing hematocolpos and acute urinary retention in an adolescent girl. Taiwan J Obstet Gynecol. 2011;50(1):118-20.

8. Lim $\mathrm{YH}, \mathrm{Ng} \mathrm{SP}$, Jamil MA. Imperforate hymen: report of an unusual familial occurrence. J Obstet Gynecol Res. 2003;29:399.

9. Eksioglu AS, Maden HA, Cinar G, Yildiz YT. Imperforate hymen causing bilateral hydroureteronephrosis in an infant with bicornuate uterus. Case Rep Urol. 2012;2012:102683.

10. Lui CT, Chan TWT, Fung HT, Tang SYH. A retrospective study on imperforate hymen and hematocolpos in a regional hospital. Hong Kong $\mathbf{J}$ Emerg Med. 2010;17(5):435-40.

11. Khan ZA. Imperforate hymen: a rare case of secondary amenorrhea. J Obstet Gynecol. 2011;31(1):91-2.

12. Abu-Ghanem S, Novoa R, Kaneti J, Rosenberg E. Recurrent urinary retention due to imperforate hymen after hymenotomy failure: a rare case report and review of the literature. Urology. 2010;78(1):180-2.

13. Anselm OO, Ezegwui UH. Imperforate hymen presenting as acute urinary retention in a 14-year old Nigerian girl. J Surg Tech Case Rep. 2010;2(2):84-6.

14. Shen MC, Yang LY. Imperforate hymen complicated with pyocolpos and lobar nephronia. J Chin Med Assoc. 2006;69(5):224-7.

15. Dominguez CE, Rock JA, Horowitz IR. Surgical conditions of the vagina and urethra. In: Rock JA, eds. TeLinde's Operative Gynaecology. 10th ed. New Delhi: Wolters Kluwer Health/Lippincott Williams \& Wilkins; 2008: 508-511.

DOI: $10.5455 / 2320-1770$. ijrcog20140965

Cite this article as: Rathod S, Samal SK, Rajsekaran A, Reddi Rani P, Ghose S. Imperforate hymen and its complications: report of two cases and review of literature. Int J Reprod Contracept Obstet Gynecol 2014;3:839-42. 